\title{
MECHANISMS OF COMPETITION IN MAMMALS DURING THE LATE NEOGENE
}

\author{
Alessandro Mondanaro 주 \\ Dipartimento di Scienze della Terra, Università degli Studi di Firenze 50121, Italy; alessandro.mondanaro@unifi.it \\ Dipartimento di Scienze della Terra, dell'Ambiente e delle Risorse, Università degli Studi di Napoli Federico II, Italy
}

\author{
KeYwORDS: \\ Predation to prey ratio; \\ Megaherbivores; \\ Apparent competition
}

\section{Bullet-Points Abstract}

- Although rare, megaherbivores negatively affect species diversity at several trophic levels.

- In contrast, it has been suggested that they favour coexistence among top predators.

- We show megaherbivores controlled ecosystem functioning in Neogene large mammals.

- Carnivores were a factor in controlling the diversity of small prey.

\section{INTRODUCTION}

Megaherbivore mammals are traditionally defined as species above $1000 \mathrm{~kg}$ (du Toit \& Owen Smith, 1989; Fritz et al., 2011). In modern-day ecosystems, this ecological category includes few species such as rhinos, elephants, the hippopotamus, gaur, yak, and the giraf$\mathrm{fe}$, and it is geographically restricted to sub-Saharian Africa and Asia. However, before the Late Pleistocene megafauna extinction, megaherbivores were much more diverse. The so-called mammal megafauna was then represented by mastodonts, mammoths, ground sloths, giant armadillos, a number of notoungulates, very large bovids, deer, and camels, plus giant kangaroos and other marsupials. Megaherbivores control the consumption of primary production excluding smaller species from accessing limited resources, and exposing them to an increased predation risk by clearing thickets of vegetation the small game usually use to hide from predators. Moreover, in virtue of their large body size, megaherbivores have virtually no predator (Fritz et al., 2011). Consequently, when abundant, megaherbivores also cause a negative effect on predators limiting their availability of prey. This ecological mechanism is known as "apparent competition" and describes the indirect competition for limiting resources. In this work, we verified the idea that apparent competition of megaherbivores on carnivores applies to Neogene to Recent large mammals at large geographic and temporal scales. Furthermore, we tested the idea that the diversity of megaherbivores positively affected the diversity of sabertoothed cats. Such species were deemed to have specialized to kill largest among prey and are said to have gone extinct once the latter vanished by the end of the Pleistocene. In contrast, evidence coming from studies of their enamel isotopic composition (Feranec, 2005), long-term analyses of their prey consumption style (DeSantis et al., 2012), modelling of prey selection in extinct guilds of carnivores (Randau et al., 2013) suggested a scarce evidence of predation mechanism by sabertooths on megaherbivores. Taking in mind this information, we tested for the association between sabertooths like $\mathrm{Ho}$ motherium Fabrini, 1890 and Smilodon Lund, 1842 and megaherbivore fossil remains (Raia et al., 2007; Van Valkenburgh et al., 2016).

\section{Materials and Methods}

We downloaded from the Paleobiology Database, NOW Database and Pangaea Database, Neogene fossil occurrences of mammals belonging to Artiodactyla, Perissodactyla, Proboscidea, Carnivora and Creodonta. The geographical range of mammal occurrences covers the entire Eurasiatic region plus the Africa continent. We supplemented these data with occurrence records from Raia et al. (2009) and other published sources. For each species, age estimates and geographical paleocoordinates of individual occurrences at fossil sites were recorded. Overall, the occurrences dataset includes 655 artiodactyls, 114 carnivores, 4 creodonts, 163 perissodactyls, 67 proboscideans, for a total of 1003 species spanning from the earliest Miocene to the Holocene, distributed over 3021 fossil localities. For each species, we compiled body size estimates from different databases. Species were divided in four ecological categories based on both diet and estimated body mass: Megaherbivores (Mega), Herbivores 

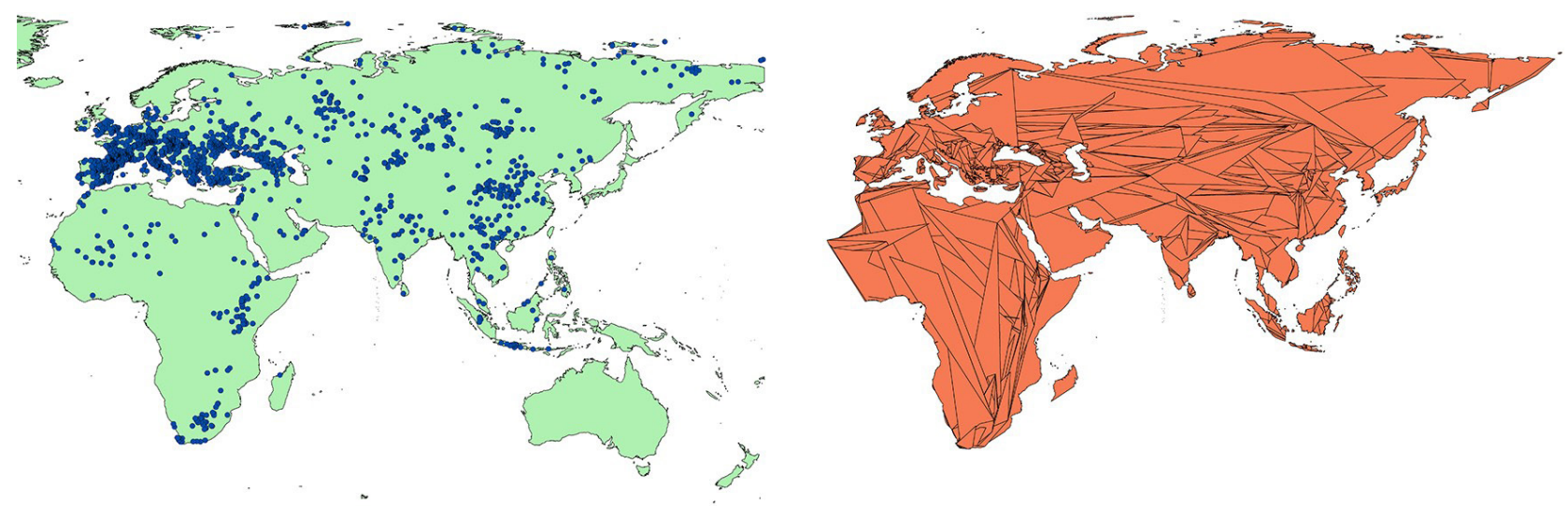

Fig. 1. The geographical distribution of fossil localities included in the analyses (left). Geographical coordinates were rotated to the present for plotting purposes. To the right, for each species it is plotted the minimum convex polygon including all species occurrences (right).

(Herb), Carnivores (Carn) and Sabertooths (Sab).

Then, we divided all record in 2-million-years-long temporal intervals maintaining a reasonably dense record for each interval. For each species and within each time bin, we constructed minimum convex polygons (MCP, Carotenuto et al., 2010) starting from its fossil occurrences (Fig.1). We overlaid a $500 \times 500 \mathrm{~km}$ grid cell resolution on each projected continent, sampling regions in an equal area context.

The use of polygons overcomes problems generated by sampling inequality per species and geographic area, by adding cells to the species presence where no fossil occurrence is indeed present, but still within the minimal range of species geographic extent. Similarly, by using a geographic grid all the fossil localities falling within a given cell (i.e. within an area of $25,000 \mathrm{~km}^{2}$ ) in a given time intervals are collapsed in a single faunal list. In this way, the effect of unequal sampling and taphonomic effects across fossil sites is avoided. We performed all analyses twice, both by using the raw fossil occurrence (henceforth "occurrence record"), and by using MCP polygons to attribute species to cells (henceforth "polygon record"). At this stage, for each cell and time bin, we excluded cells with $<5$ species overall, or lacking any predator or prey, either.

After that, we computed the ratio between the number of "predators" (Carnivores plus Sabertooths) and "preys" (Meso- and Megaherbivores) for each geographic cell within a given time bin. We also computed the body size range of Predators and Prey for each cell within each time bin in order to retrieve the degree of overlap between Predators and Prey body mass distributions (PPR-overlap).

With these variables, we performed six different regressions using the number of species in each category and their estimated body sizes per cell, and separately per time bin. The regression (1) of predator-to-prey ratio (PPR) against the number of megaherbivores (Mega) was calculated to test for the effect of apparent com- petition of the latter on Predators. Predators (Pr) were regressed (2) against Herbivores (Herb) to verify for the relationship between the richness of predators and non-megaherbivore prey. The regression (3) between Mega and Herb was computed to test for competition between species belonging to these categories, to test the idea that megaherbivores did control the diversity of Herb. The richness of Sabertooths (Sab) was regressed (4) against Mega in order to test the idea that sabertooths preferentially preyed upon megaherbivores. Similarly, the diversity of large carnivores $(\mathrm{Pr}>100)$ was regressed against Mega (5). Eventually, we regressed (6) PPR against Overlap in order to verify if an increment in degree of overlap is correlated to a higher chance of predation on megaherbivores, under the observation that larger predator might tackle down comparatively larger prey (Van Valkenburgh et al., 2016). All of the six regressions were controlled for spatial autocorrelation by using GLS models. In details, we fitted the related empirical semivariograms with 4 models (Gaussian, Spherical, Rational Quadratic, Exponential) and then updated an OLS regression by these 4 spatial correlation structures. The outcomes of these five models (OLS and the 4 spatially structured) were then compared by means of ANOVA.

Consecutive intervals within the same geographical place share a number of species. This means that the data could be temporally autocorrelated, thereby originating spurious associations between the variables. To address the issue of temporal autocorrelation, we used the autoregressive integrated moving average (ARIMA) model. ARIMA works by regressing a variable point value on previous (older) datapoints, at some (fitted) distance (i.e. lag). The best lag between variables was estimated via cross-correlation, and the existence (and removal thereof) of temporal autocorrelation was assessed by means of Breush-Godfrey test (McMurry \& Politis, 2015). To produce ARIMA models, we used the polygons record to maximize the 
number of datapoints. However, rather than using the $500 \mathrm{~km}$ wide cells we opted for $2000 \times 2000 \mathrm{~km}$ cells and selected only cells possessing at least 10 species and at least one carnivore species per time bin, for at least 6 time bins. We performed the ARIMA regressions of PPR against Mega, Pr against Herb, Mega against Herb, and $\mathrm{Pr}>100$ against Mega.

\section{Results AND Discussions}

The results were qualitatively very similar using either the polygon and the occurrence record. The polygon record is much more dense and less affected by sampling issues, and was therefore used to perform ARIMAs.

As far as the six regression are concerned, the predator to prey ratio (PPR) is significantly and negatively correlated to the number of megaherbivores in one fourth of the intervals. No positive relationship applies. The number of predators (Pr) is negatively and significantly related to the number of mesoherbivores (Herb) in 6 out of 8 intervals (75\%) (Tab. 1). Nearly two-thirds of the times ( 5 times in 8 intervals, $62.5 \%$ ) the richness of megaherbivores (Mega) is inversely and significantly related to herbivore (Tab. 1). There is no positive relationship between the diversity of sabertooths (Sab) and Mega. The richness of large predators (species $>100 \mathrm{~kg}$ in body size) is not significant associated to the number of megaherbivores (Tab. 1). The regression between Mega and $\operatorname{Pr}>100$ is significant and negative. Finally, the degree of overlap between the body size distribution of predators and prey is positively and significantly related to PPR six times (66.7\%) (Tab. 1). A significant and negative relationship occurs once (Tab. 1). As regards the first (most recent) interval, all the regression results are consistent with the apparent competition theory. The spatial distribution of PPR in the Old World during the last interval shows no significant spatial autoregression. The results of ARIMA regressions confirm the existence of a negative relationship between the number of predators (Pr) and mesoherbivores (Herb) in four out of five valid cells. The number of megaherbivores is negatively associated to the number of mesoherbivores (Mega-Herb) in three cells out of four. PPR is always negatively associated to Mega. Finally, the number of megacarnivores (i.e. predators above $100 \mathrm{~kg}$ in body mass) is negatively associated to the number of megaherbivores twice, and positively associated as many times. Cross-correlation applied to the residuals consistently shows a lag of 1 to 3 intervals, and mostly of 2 (i.e. $4 \mathrm{Myr}$ ) between herbivores and predators and megaherbivores respectively, meaning that Pr and Mega negatively affected the diversity of mesoherbivores in successive temporal intervals.

These results indicate that large carnivores paid a price to the ecological dominance of megaherbivores. As megaherbivores diversified, the biomass available

\begin{tabular}{|c|c|c|c|}
\hline \multirow{2}{*}{$\begin{array}{l}\text { Regression } \\
\text { model (y-x) }\end{array}$} & \multicolumn{2}{|c|}{ Significant } & \multirow{2}{*}{$\begin{array}{c}\text { Non- } \\
\text { significant }\end{array}$} \\
\hline & Positive & Negative & \\
\hline PPR-Mega & 0 & 2 & 7 \\
\hline Pr-Herb & 0 & 6 & 2 \\
\hline Mega-Herb & 0 & 5 & 3 \\
\hline Sab-Mega & 0 & 1 & 7 \\
\hline Pr $>100-$ Mega & 0 & 1 & 7 \\
\hline PPR-Overlap & 6 & 1 & 2 \\
\hline
\end{tabular}

Tab. 1. Summary statistics for the regressions of the number of species within ecological categories per cell.

to carnivores reduced, exactly because megaherbivores are hard to kill, and smaller herbivores were significantly outcompeted by the larger species. Indeed, rather than the apparent competition of megaherbivores on carnivores, the most robust generalizations we derive from this study is that the diversity of mesoherbivores is negatively affected by the diversity of both carnivores and megaherbivores. This implies that predation and direct competition increases extinction probability in small herbivores, as often suggested to occur for living prey species (Fritz et al., 2002; Malhi et al., 2016). Some sabertooths were probably able to dispatch juveniles of very large prey species such as mammoths or ground sloths. This was suggested to exercise a topdown control on megaherbivores (Van Valkenburgh et al., 2016). While killing juvenile megaherbivore is perfectly feasible for a top predator, and not contradicted by our data, we suggest these were probably not their most profitable prey, and more importantly, megaherbivores diversity did not sustain higher carnivore diversity.

\section{ConCLUSIONS}

We found evidence that, in the long run, such pervasive dominance of megaherbivores translates into higher extinction rate upon (primarily) small prey and (secondarily) predatory species, thereby altering predator to prey ratios (Raia et al., 2007; Meloro \& Clauss, 2012). Such fact is further conceivable considering that small prey populations tend to be limited by predation, while larger species are mainly controlled by resources (Terborgh et al., 2010). It must be noted that very large predators and sabertooths were much less influenced by the diversity of megaherbivores than mesoherbivores. Together with the quite consistent, positive relationship between body size overlap and PPR, this indicates that very large carnivores did actually go for larger prey than other carnivores on average. However, this is also consistent with their larger average body size, and not just with any preference for megaherbivores. Indeed, large predators do not specialize on the larger prey, they just exploit a wider prey spectrum (Radloff \& du Toit, 2004). 


\section{ACKNOWLeDGeMENTS}

I'm grateful to Lorenzo Rook, Pasquale Raia e Franscesco Carotenuto who shared with me the ideas ehich are the base of this work.

\section{REFERENCES}

Carotenuto F., Barbera C. \& Raia P. (2010). Occupancy, range size, and phylogeny in Eurasian Pliocene to recent large mammals. Paleobiology, 36, 399-414.

DeSantis L. R. G., Schubert B. W., Scott J. R. \& Ungar P. S. (2012). Implications of diet for the extinction of saber-toothed cats and American lions. PLoS ONE, 7: e52453. http://dx. doi.org/10.1371/journal. pone. 0052453

du Toit J. T. \& Owen-Smith N. (1989). Body size, population metabolism, and habitat specialization among large African herbivores. American Naturalist, 133 (5), 736-740. http://dx. doi.org/10.2307/2462079.

Feranec R. S. (2005). Growth rate and duration of growth in the adult canine of Smilodon gracilis, and inferences on diet through stable isotope analysis. Bulletin of the Florida Museum of Natural History, 45, 369-377.

Fritz H., Duncan P., Gordon I. \& Illius A. (2002). Megaherbivores influence trophic guilds structure in African ungulate communities. Oecologia, 131, 620-625. http:// dx.doi.org/10.1007/s00442-002-0919-3.

Fritz H., Loreau M., Chamaillé Jammes S., Valeix M. \& Clobert J. (2011). A food web perspective on large herbivore community limitation. Ecography, 34, 196-202.

Malhi Y., Doughty C. E., Galetti M., Smith F.A., Svenning J.-C. \& Terborgh J. W. (2016). Megafauna and ecosystem function from the Pleistocene to the Anthropocene.
Proceedings of the National Academy of Sciences, 113: 838846. http://dx.doi.org/10.1073/pnas.1502540113.

McMurry T. L. \& Politis D. N. (2015). High-dimensional autocovariance matrices and optimal linear prediction. Electronic Journal of Statistics, 9: 753-788.

Radloff F. G. T., du Toit J. T. \& Johan T. (2004). Large predators and their prey in a southern African savanna: a predator's size determines its prey size range. Journal of Animal Ecology, 73: 410-423.

Raia P., Meloro C. \& Barbera C. (2007). Inconstancy in predator/prey ratios in Quaternary large mammal communities of Italy, with an appraisal of mechanisms. Quaternary Research, 67: 255-263. http://dx.doi. org/10.1016/j.yqres.2006.10.005.

Randau M., Carbone C. \& Turvey S. T. (2013). Canine evolution in sabretoothed carnivores: natural selection or sexual selection? PLoS ONE, 8, e72868.

Terborgh J., Holt R. D. \& Estes J. A. (2010). Trophic cascades: what they are, how they work, and why they matter. In Terborgh, J., Estes, J.A. (Eds.), Trophic Cascades: Predators, Prey and the Changing Dynamics of Nature. Island Press, USA, pp. 1-18.

Van Valkenburgh B., Hayward M. W., Ripple W. J., Meloro C. \& Roth V. L. (2016). The impact of large terrestrial carnivores on Pleistocene ecosystems. Proceedings of the National Academy of Sciences, 113 (4): 862-867. http:// dx.doi.org/10.1073/pnas.1502554112.

Manuscript received 5 August 2018

Received after revision 16 October 2018 Accepted 22 October 2018 